\title{
DISTRIBUIÇÃO ESPACIAL E TOPONÍMIA DAS PRAÇAS DE CURITIBA-PR
}

\author{
Daniela Biondi ${ }^{1}$, Everaldo Marques de Lima Neto ${ }^{2}$
}

\section{RESUMO}

Nas cidades, a praça é uma das tipologias de áreas verdes mais acessíveis a população urbana porque pode desempenhar as funções ecológicas, estéticas e sociais em qualquer escala. Embora Curitiba seja conhecida nacionalmente pelo número e qualidade de suas áreas verdes, existe muito pouca informação sobre a participação quantitativa e espacial das praças na malha urbana. Isto provavelmente auxiliaria para o planejamento de áreas verdes. O objetivo deste trabalho foi caracterizar as praças de Curitiba através de sua distribuição espacial e toponímia. Foram coletadas informações sobre as regionais administrativas, bairros, áreas das praças e bairros, nomes das praças. Com estas informações foram calculados os seguintes índices: IAPH (índice de áreas de praças nas regionais por habitante), IAPR (índice de área de praça por regional), NPR (número de praças por regional), IAPH (índice de área de praça por habitante) e IAPB (índice de área de praça por bairro). Os maiores valores destes índices nas regionais variaram em função da taxa de urbanização. O maior IAPH foi para a regional CIC e os maiores IAPR e NPR para regional Matriz. Seis bairros apresentaram os índices IAPH e IAPB iguais a zero. A grande maioria das praças apresentou topônimos denominados de antropotoponímicos.

Palavras-chave: áreas verdes; planejamento; índices de praças.

\section{SPATIAL DISTRIBUTION OF SQUARES AND TOPONYMY CURITIBA-PR}

\section{ABSTRACT}

In cities, the square is one of the types of green areas more accessible to urban population because it can act as ecological, social and aesthetic at any scale. Although Curitiba is known nationally for the number and quality of its green areas, there is very little information about the spatial and quantitative participation of the urban fabric squares. It probably would help in the planning of green areas. The objective of this study was to characterize the squares of Curitiba through its spatial distribution and toponymy. Data were collected on the administrative regions, districts, areas of squares and neighborhoods, names of servicemen. With this information we calculated the following indexes: SACRI (squares areas per capita regional index), SARI (square area for regional index), SNR (squares number per regional), SAI (square area per inhabitant) and SAN (square area by neighborhood). The highest values of this index varied with the regional rate of urbanization. The SACRI was greater for the regional CIC and the largest was for SARI and SNR Matriz regional. Six districts had rates SACRI and SAN zero. Most of the squares had called toponyms anthropic-toponymic.

Key-words: green spaces; planning; rates of squares.

\footnotetext{
${ }^{1} \mathrm{Dr}^{\mathrm{a}}$. Professora Associada, Universidade Federal do Paraná. Departamento de Ciências Florestais, Curitiba - PR, dbiondi@ufpr.br

${ }^{2}$ Engenheiro Florestal, Doutorando em Engenharia Florestal, Universidade Federal do Paraná. Curitiba - PR, everaldo.limaneto@gmail.com
} 


\section{INTRODUÇÃO}

A palavra praça provém do latim platea, e do grego platýs, resume o sentido da ágora grega e do fórum romano, o espaço do público e da reunião. A praça é considerada um cenário de festas, passeios, reuniões, comércio, permanência, encontros e desencontros, descanso, convulsões sociais; obra do homem no arco do tempo que transcende o próprio; registro vivo a perpetuar na história; retrata modismos e estilos de cada época; senhora dos espaços públicos, desafiou séculos; impassível, superou o abandono, a indiferença e as transformações ao longo do tempo; lugar de encontro ou de promessa de encontro (SANTOS, 2007).

A praça foi, na maioria das vezes, o palco de diversos fatos relevantes ocorridos na história, tais como: na ágora, Sócrates fora colocado sob processo; no Fórum de Roma nasceu o Império homônimo; a Praça de São Petersburgo foi o berço da Revolução Comunista na extinta União Soviética; na Plaza de Mayo, Buenos Aires, surgiu e resiste o movimento de mães que buscam seus filhos desaparecidos durante o regime militar; a Praça de Tiananmen mais conhecida como Praça da Paz Celestial, em Pequim, é símbolo e testemunha da agonia e morte dos que buscavam democracia e liberdade na primavera de 1989 (DE ANGELIS e CASTRO, 2004).

Tanto no ocidente como no oriente, as praças surgiram da cultura religiosa e política. A cultura islâmica possuía um espaço livre denominado de “madjan” e na Itália as praças eram vitais para o funcionamento do poder político. Esse e outros exemplos estão presentes em muitas culturas (BURGOS, 2003).

As primeiras praças não possuíam vegetação e sua função primordial era o comércio e as relações de compra, de venda e de troca de informações. Só depois do advento da industrialização é que as praças passaram a obter vegetação e outras funções como: estética, psicológica e ambiental (GONÇALVES, 2010).

No Brasil, só a partir do século XIX que a arborização das ruas e praças se consolidou como figuras comuns da gramática urbana (MACEDO, 2003). Juntamente com a rua, a praça consiste em um dos mais importantes espaços públicos urbanos da história da cidade no país, tendo, desde os primeiros tempos de colônia desempenhado um papel fundamental no contexto das relações sociais em desenvolvimento (MACEDO, 2002).

Uma praça pode ser definida, de maneira ampla, como qualquer espaço público urbano, livre de edificações que propicie convivência e/ou recreação para os seus usuários (VIERO, 2009). Além de ser considerado um espaço público e com função de convívio social, deve estar inserida na malha urbana como elemento organizador da circulação e de amenização pública, contendo expressiva cobertura vegetal, mobiliário lúdico, canteiros e bancos (CARNEIRO e MESQUITA, 2000).

A praça pode desempenhar diversas funções, tais como: ecológica - desempenhada pela presença de vegetação e atrativo de animais, presença de solo permeável, melhoria do clima e qualidade do ar; estética - ligada à diversificação da paisagem de forma agradável aos olhos de quem a vê e ao embelezamento da cidade; e psicológica intimamente ligada ao relaxamento obtido pelo contato com o natural, entre outros (DOURADO, 2009). Possibilita também uma integração voluntária à vida de agrupamentos recreativos sociais e culturais (COSTA et al., 2010); simbólicos, porque se tornam objetos referenciais e cênicos na paisagem da cidade, exercendo importante papel na identidade do bairro ou da rua (ROBBA e MACEDO, 2010).

As praças são como pequenos espaços na malha urbana, deveriam ter suas funções protegidas por lei, inclusive com relação à manutenção do seu entorno com edificações de até um ou, no máximo, dois pavimentos, por questões de escala e proporção (CARNEIRO e MESQUITA, 2000).

Considerando a contextualização acima pode-se afirmar que a praça é uma das tipologias de áreas verdes inseridas no meio urbano mais reconhecida no mundo. Embora existam muitas terminologias de Daniela Biondi et al.. 
áreas verdes adotadas por diferentes Prefeituras, o termo "praça" é o mais presente e identificado em qualquer cidade do Brasil.

A cidade de Curitiba é conhecida nacionalmente pelo número e qualidade de suas áreas verdes urbanas. Segundo IPPUC (2011), Curitiba está entre as grandes cidades do mundo premiadas pela edição 2010 da competição World Design Capital - Capital Mundial do Design (WDC) - realizada em Seul, na Coréia do Sul. Curitiba foi escolhida na categoria Política de Desenvolvimento Urbano e é citada como uma cidade que tem um plano diretor para orientar o crescimento, contemplando transportes, circulação, uso da terra e meio ambiente de forma integrada. Inclui ainda medidas de preservação de áreas verdes e das heranças históricas e culturais.
Segundo levantamento da Secretaria Municipal de Meio Ambiente (SMMA), em 2000, o município contava com 30 unidades de parques e bosques, 11 núcleos ambientais, 05 jardins ambientais, 54 largos, 15 eixos de animação e 330 jardinetes (SMMA, 2006) e 453 praças (IPPUC, 2011).

Dos tipos de áreas verdes existentes em Curitiba, as que têm mais informações científicas são os parques. Não há informação sobre a participação quantitativa e espacial das praças na malha urbana. Isto provavelmente auxiliaria no planejamento de áreas verdes facilitando a percepção dos bairros com menos ou nenhuma praça.

O objetivo deste trabalho foi caracterizar as praças de Curitiba através de sua distribuição espacial e toponímia.

\section{MATERIAL E MÉTODOS}

\section{Localização e caracterização da área de estudo}

A pesquisa foi realizada na cidade de Curitiba, Paraná, Brasil (FIGURA 1) e ocupa uma área de $432,17 \mathrm{~km}^{2}$. A capital paranaense localiza-se no Primeiro Planalto a uma altitude média de 934,6 m acima do nível do mar e situa-se aproximadamente a $25^{\circ} 25^{\prime}$ de latitude sul e $49^{\circ} 17^{\prime}$ de longitude oeste. Segundo a classificação de Köppen, a cidade de Curitiba localiza-se em região climática do tipo Cfb, com clima subtropical úmido, mesotérmico, sem estação seca, com verões frescos e invernos com geadas freqüentes e ocasionais precipitações de neve. De acordo com o último estudo realizado pelo IPPUC entre os anos de 1998 e 2001, Curitiba apresenta temperatura média de $17,48^{\circ} \mathrm{c}$, precipitação média anual de 1571,28 mm e umidade média relativa do ar de 78,87\% (IPPUC, 2011).

A vegetação de ocorrência natural é composta da Floresta Ombrófila Mista e Estepe GramíneoLenhosa (RODERJAN et al., 2002). A cobertura vegetal foi estimada em 12.994,50 $\mathrm{m}^{2}$ (VIEIRA, 2006) equivalente a $30 \%$ do território municipal.
Segundo Hardt (2000), incluindo a vegetação introduzida, 62,81\% do território era composto por áreas permeáveis, formadas, em grande parte, por áreas verdes, que correspondiam a 56,83\% do município; as áreas com vegetação não arbórea compreendiam a $43,24 \%$, enquanto as com cobertura arbórea estavam presentes em 13,59\% da cidade.

De acordo com a Secretaria Municipal de Meio Ambiente - SMMA no ano 2000, o total de área verde disponível na cidade, era de 77.901.198,20 m², e o índice de cobertura vegetal, de 49,08 $\mathrm{m}^{2} /$ habitantes (SMMA, 2000).

A divisão político-administrativa do município de Curitiba origina 75 bairros que estão agrupados em nove regionais administrativas: Bairro Novo, Boa Vista, Boqueirão, Cajuru, CIC, Matriz, Pinheirinho, Portão e Santa Felicidade, como mostra a FIGURA 2 (IPPUC, 2011). 
Figura 1. Localização da cidade Curitiba-PR

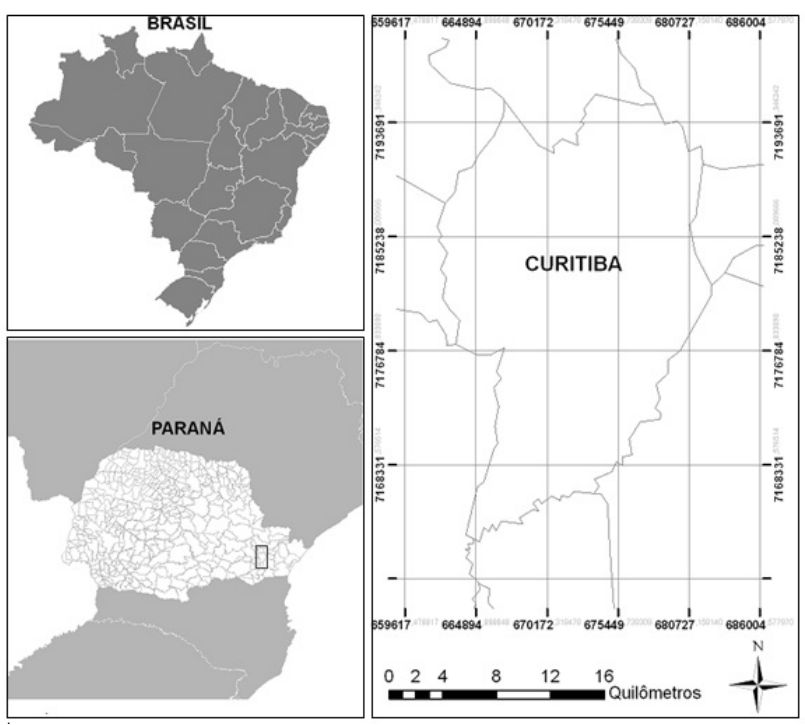

\section{Procedimentos metodológicos}

Todas as informações referentes às praças de Curitiba foram adquiridas pelo Instituto de Pesquisa e Planejamento Urbano de Curitiba (IPPUC, 2011), tais como: regionais administrativas (FIGURA 2), bairros, áreas das praças, área dos bairros, nomes das praças e localização. Com estas informações foram calculados os seguintes índices:

a) IAPH - Índice da Área de Praça por Habitante: corresponde ao somatório das áreas das praças dividido pelo número de habitantes;

$L A F H=\sum_{H a b}^{A P}$

Onde:

$\mathrm{AP}=$ área das praças da regional;

$\mathrm{Hab}=$ número de habitantes da regional.

b) IAPR (\%) - Índice da Área de Praça por Área da Regional: corresponde ao somatório das áreas das praças das regionais dividido pela área da regional. O resultado multiplicado por 100 , gerando um índice percentual;

$$
E A P R=\left(\sum \frac{A P}{A R}\right) \times 100
$$

Onde:
$\mathrm{AP}=$ área das praças da regional;

$\mathrm{AR}=$ área da regional.

c) IAPB (\%) - Índice da área das praças por bairro: é resultado da somatória da área das praças do bairro, dividido pela área do bairro, multiplicado por 100.

\section{EAPE $=\frac{\sum A P r}{A B} \times 100$}

Onde:

$\mathrm{APr}=$ área das praças em cada bairro;

$\mathrm{AB}=$ área do bairro.

d) NPR - Número de praças em cada Regional.

e) NPB - Número de praças em cada Bairro.

O estudo da Toponímia ou dos nomes das praças de Curitiba foi baseado nas informações de De Angelis e De Angelis Neto (2001) e De Angelis et al. (2004). 
Figura 2. Unidades Administrativas de Curitiba: Regionais e Bairros
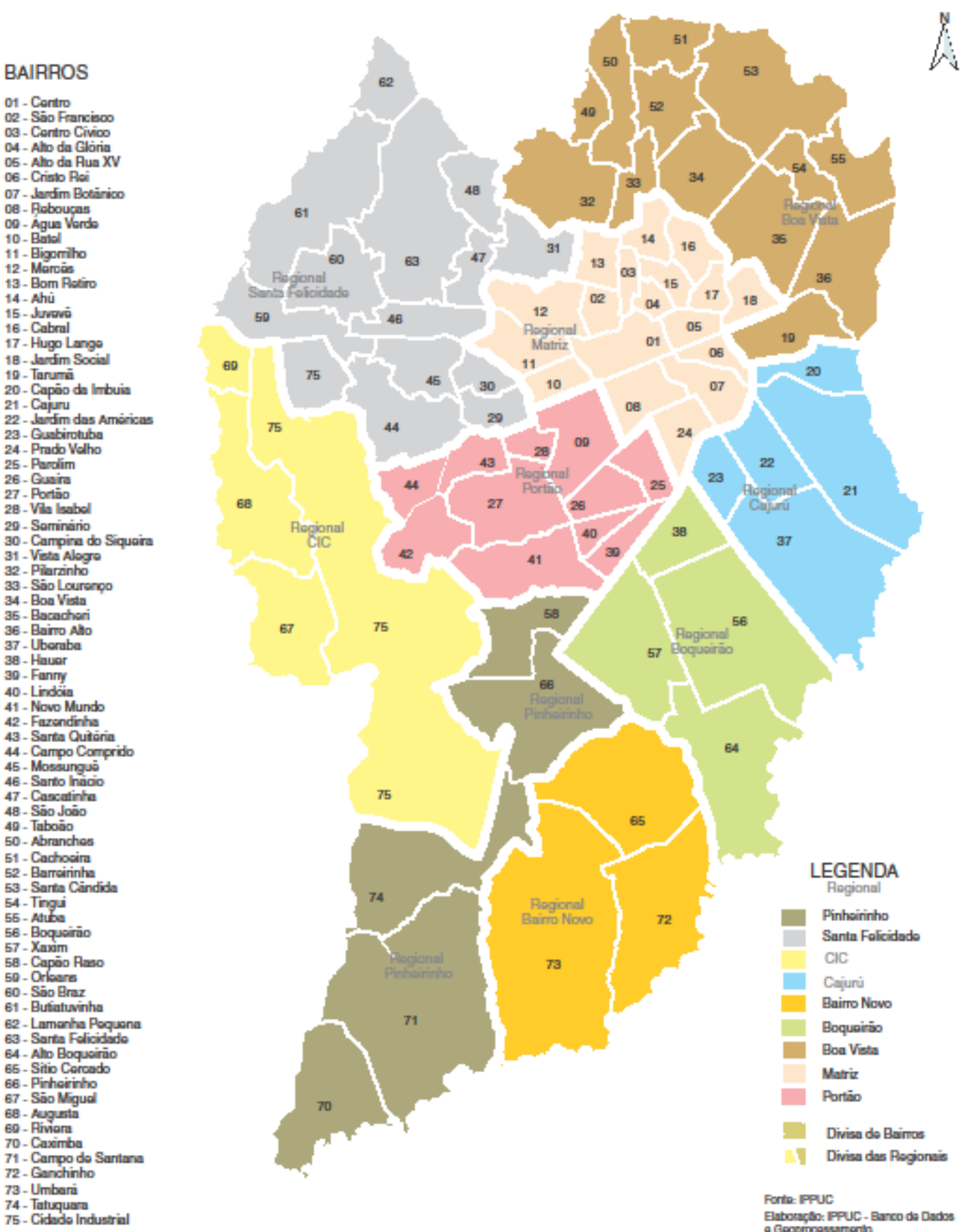

68

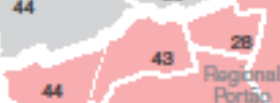

00

4. 24
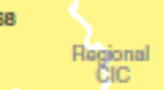

27
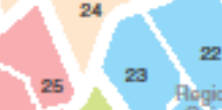
22
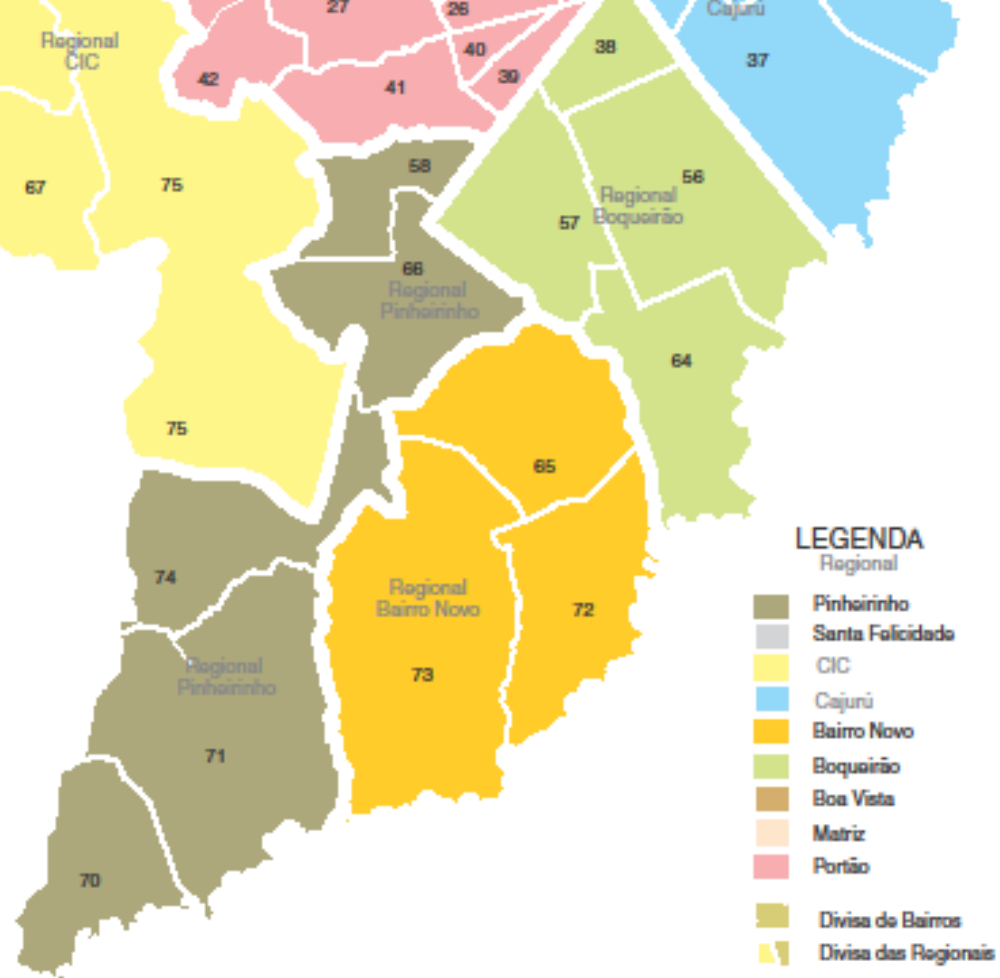

Forte: PPUC

Elaboracto: FPUC - Barco da Dados - Clocprocossarmonto Earats - 1:150 000

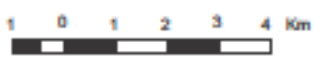

FFUC Instituto de Pesquisa e Planejamento Urbano de Curitiba - SIN - Banco de Dados

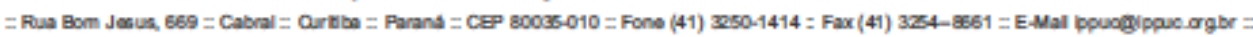

Fonte: IPPUC (2011) 
RESULTADOS E DISCUSSÃO

Distribuição da área de praças nas unidades administrativas de Curitiba

Nesta pesquisa foram encontradas 453 praças na cidade de Curitiba ocupando uma área de 2.710.538 $\mathrm{m}^{2}$ (TABELA 1). Considerando que esta área só é ocupada pela categoria de praças, para uma cidade do porte de Curitiba, não é uma área pequena. A cidade de Havana-Cuba, por exemplo, conta com 99.453.130,80 $\mathrm{m}^{2}$ com a ocupação de todas as categorias de áreas verdes, incluindo ainda a arborização de ruas e avenidas (Padron et al., 2001).

Tabela 1. Índices espaciais aplicados nas praças das regionais administrativas da cidade de Curitiba-PR

\begin{tabular}{lcccccc}
\hline Regional & $\begin{array}{c}\text { Área de Praças } \\
\mathbf{( m}^{\mathbf{2}}\end{array}$ & $\begin{array}{c}\text { Área da } \\
\text { Regional } \mathbf{( m}^{\mathbf{2}} \mathbf{)}\end{array}$ & $\begin{array}{c}\text { Habitante } \\
\mathbf{( 2 0 1 0 )}\end{array}$ & IAPH & IAPR & NPR \\
\hline Matriz & 487.256 & 36.288 .000 & 210.891 & 2,31 & 1,34 & 88 \\
Boqueirão & 311.715 & 39.859 .000 & 206.881 & 1,51 & 0,78 & 41 \\
Cajuru & 280.817 & 14.086 .000 & 221.005 & 1,27 & 1,99 & 49 \\
Bairro Novo & 216.308 & 44.793 .000 & 140.130 & 1,54 & 0,48 & 30 \\
CIC & 457.216 & 43.378 .000 & 172.573 & 2,65 & 1,05 & 63 \\
Pinheirinho & 146.935 & 56.767 .000 & 151.487 & 0,97 & 0,26 & 28 \\
Santa Felicidade & 266.581 & 69.579 .000 & 155.465 & 1,71 & 0,38 & 44 \\
Boa Vista & 338.304 & 60.509 .000 & 250.651 & 1,35 & 0,56 & 72 \\
Portão & 205.406 & 31.218 .000 & 255.400 & 0,80 & 0,66 & 38 \\
\hline \multicolumn{1}{c}{ TOTAL } & 2.710 .538 & 396.477 .000 & 1.764 .485 & 1,54 & 0,68 & 453 \\
\hline
\end{tabular}

LEGENDA:
IAPH = Índice de áreas de praças nas regionais por habitante; IAPR = Índice de área de praça por regional; NPR = Número de praças por regional

Observa-se que a regional Matriz, constituída predominantemente pelo bairro central, apresenta maior área de praças e maior número de praças (TABELA 1). Este aspecto é muito positivo para uma cidade porque geralmente nesta área é onde se concentra o maior número de áreas impermeáveis (construções e vias públicas) e pessoas. No contexto ecológico, as praças poderão proporcionar maior conforto aos residentes e transeuntes principalmente se apresentarem alguma vegetação. Além disso, as praças nos centros urbanos desempenham um forte papel social para a realização de manifestações políticas e culturais.

Krug (1953) recomenda a utilização das áreas centrais para a introdução de áreas verdes embora estas áreas tenham preços elevadíssimos e indenizações difíceis. Griffith e Silva (1987) consideram importante a aquisição tanto de áreas centrais como as áreas periféricas para o planejamento de áreas verdes.

Harder et al. (2006) definem praças como pontos de encontro cuja principal função é incentivar a vida comunitária; são áreas verdes com dimensões, em geral, entre $100 \mathrm{~m}^{2}$ e 10 ha.

Em Curitiba-PR, o Decreto 427/83 denominam e definem as áreas verdes de acordo com suas características, dentre elas, as praças são definidas como áreas com mais de $2.500 \mathrm{~m}^{2}$, admitida aproximação de 10\% (LIZ, 2011).

Os resultados obtidos nesta pesquisa, em que a regional Matriz apresenta maior número de praças, não deve ser associado a maior cobertura vegetal. Segundo Vieira e Biondi (2008) analisando a cobertura vegetal da cidade Curitiba em dois períodos, verificaram que a regional Matriz apresentou a menor percentagem de participação de cobertura vegetal em 1986 e a segunda menor Daniela Biondi et al.. 
percentagem em 2004, precedida da regional do Portão. O motivo de serem essas as regionais com menor índice de cobertura vegetal se explica pelo fato de, segundo Vieira (2006), serem regionais que apresentam altos índices de urbanização. Isto explica também a razão do menor IAPH da regional Portão $(0,80)$.

É preciso atentar que a maioria das definições de áreas verdes urbanas inclui, mesmo que em pequenas proporções, a presença de áreas antropizadas, incluindo, assim, áreas construídas e extrapolando o conceito de espaços naturais e vegetados (Vieira e Biondi, 2008). Além disso, Robba e Macedo (2010) esclarecem que na cidade contemporânea, a definição de praça é bastante abrangente porque inclui desde pequenas áreas destinadas ao lazer esportivo em bairros habitacionais até os grandes complexos de articulação urbana em áreas centrais.

Observa-se na TABELA 1 que o maior índice de área de praça por habitante (IAPH) foi encontrado na regional CIC, refere-se ao setor industrial da cidade que é uma das regionais que apresenta maior quantidade de cobertura vegetal, segundo Vieira (2006). Neste caso, pode ser que a praça seja uma das tipologias de áreas verdes responsável por esta cobertura vegetal, principalmente por ser composta também por bairros residenciais. Segundo Cavalheiro et al. (1999), cobertura vegetal é a projeção do verde em cartas planimétricas, considerando os espaços livres, os espaços construídos e os espaços de integração, além das Unidades de Conservação e da zona rural.

A regional Pinheirinho apresentou a menor área ocupada com praças, menor índice de área de praça por regional (IAPR) e menor número de praças por regional (NPR). Embora Vieira (2006) tenha constatado que a regional Pinheirinho possui a menor taxa de ocupação urbana (41,43\%), a quantidade de praças ainda é uma tipologia de área verde com pouca expressão nesta regional.

Quando se analisa a densidade populacional, número de praças e número de bairros nas regionais de Curitiba (FIGURA 3), a regional Matriz se sobressai novamente apresentando maior número de bairros.
Isto justifica a matriz ter maior número de praças. Uma das mais antigas propostas de distribuição de áreas verdes é a do Krug (1953) em que diz que o ideal é distribuir certa superfície de jardins públicos para um determinado número de habitantes. Diz ainda que, em geral, as zonas centrais são mais densamente povoadas e por conseqüência devem ter maior área de jardins públicos.

Vieira (2006) afirma que há várias formas de se abordar a questão da eficiência das áreas verdes urbanas. Uma delas é a recomendação da ONU (Organização das Nações Unidas) que é de índice de $12 \mathrm{~m}^{2}$ por habitante de área verde nas cidades (Biondi, 2000). A outra é da OMS (Organização Mundial da Saúde) que estabelece o índice de 12 a 15 $\mathrm{m}^{2}$ / habitante. A distribuição e qualidade das áreas verdes têm um importante papel e grande peso na qualidade de vida urbana (Biondi, 1995). Os índices quantitativos isolados, para Milano (1991b), normalmente expressam pouco a realidade, devendo ser feitas avaliações e análises quali-quantitativas. Com ênfase, Guzzo (2002) afirma que uma informação quantitativa geral não expressa como as áreas se encontram, como são utilizadas e sua distribuição dentro da cidade.

Na FIGURA 3, observa-se que a regional Cajuru apresentou o maior índice de área de praça por regional. Isto pode não está indicando que a regional apresenta um alto índice de áreas verdes. Pode ser que a tipologia praça seja a única expressão de área verde nesta regional. Vale salientar ainda que as praças, embora sejam consideradas áreas verdes, podem ter ou não cobertura vegetal.

Segundo Vieira e Biondi (2008), a regional Cajuru é a que mais perdeu cobertura vegetal nos últimos anos, em função de sua localização, próxima às áreas de urbanização mais densas do município. Segundo essas autoras, uma "saturação" das áreas de ocupação urbana mais tradicional pode ter intensificado o processo de urbanização na área contígua, onde se encontra a regional Cajuru, indicando, portanto, que grande parte da pouca cobertura vegetal que existia nessa regional "cedeu" lugar à urbanização que se expandia.

DISTRIBUIÇÃO ESPACIAL E TOPONÍMIA... 
O confronto dos resultados destas pesquisas reflete a importância e a contribuição das praças, principalmente em regionais com alta taxa de urbanização.

Figura 3. Relação da densidade populacional, número de praças e número de bairros nas regionais de Curitiba-PR

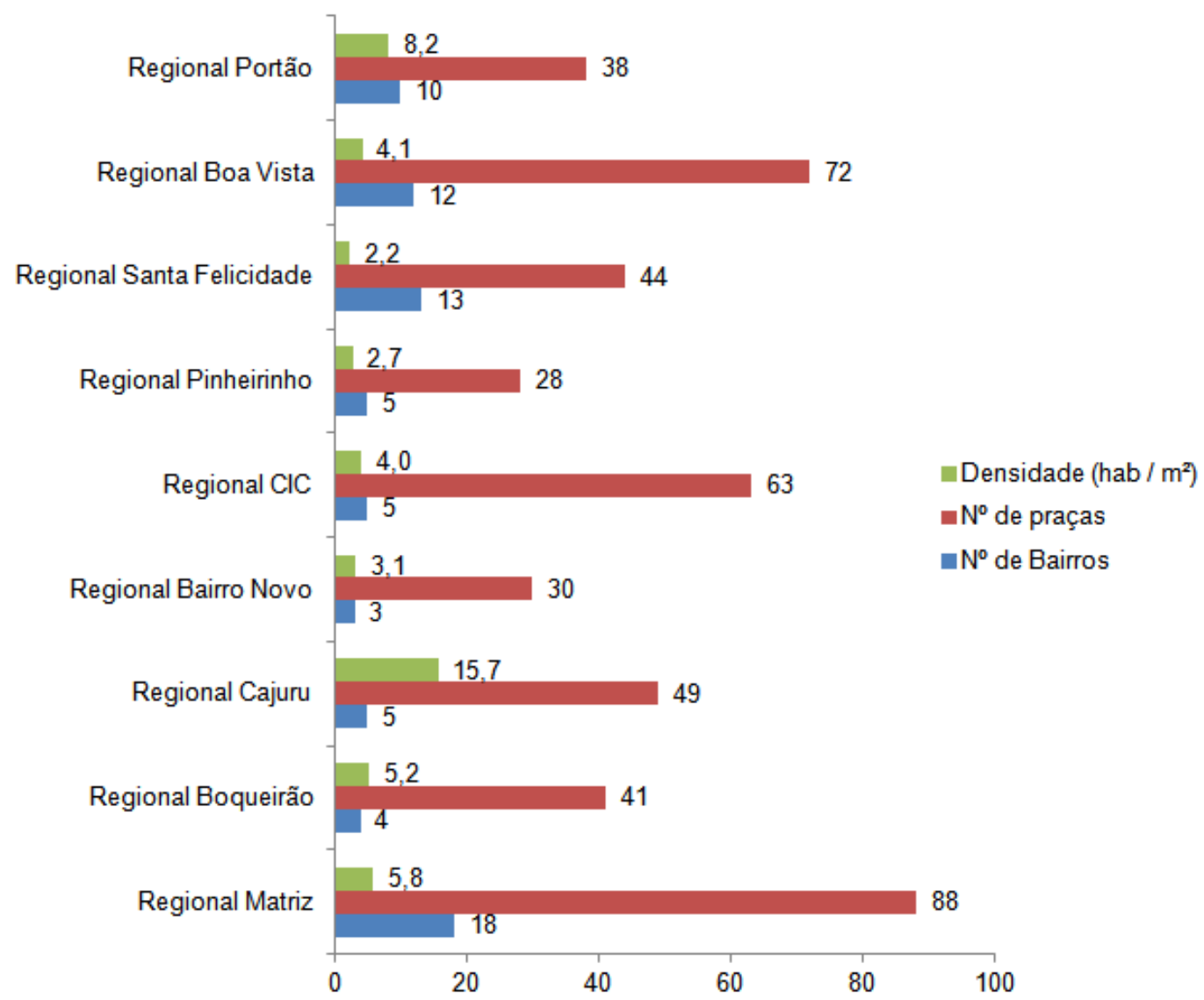

\section{Distribuição da área de praças nos bairros de Curitiba}

Observa-se na TABELA 2 que seis bairros não têm praça. Três deles (São Miguel, Riviera, e Caximba) são justificados porque são áreas de expansão da cidade e não apresentam o processo de urbanização consolidado. Este resultado poderia estar associado também ao baixo número de habitantes, mas isto também precede para o bairro da Caximba. Robba e Macedo (2010) afirmam que, sem usuários o espaço público perde seu significado e é presa fácil da voracidade dos agentes da transformação urbana, tanto por parte do poder público quanto pelo mercado imobiliário.

Além disso, existe outro aspecto a ser pensado com relação aos bairros São Miguel e Reviera que estão inseridos na regional CIC. Segundo Vieira (2006), é uma das regionais que apresenta maior quantidade de cobertura vegetal. E de acordo com a TABELA 1, ocupa o terceiro lugar dos maiores números de praças. Então a causa mais provável da ausência de praças nestes bairros deve ser o baixo número de habitantes.

Já para a ausência de praças no bairro de São Lourenço, a única justificativa plausível é a presença marcante de parque com o mesmo nome que é muito bem equipado e bastante freqüentado pelos moradores do bairro. O mesmo ocorre com o bairro da Orleans que é bem próximo a um dos maiores parques de Curitiba (Parque Barigui). É questionável que a população não reivindique a criação deste tipo de área verde, mesmo que seja uma praça de pequena extensão. Segundo Biondi (2008), qualquer pessoa pode ingressar na justiça pleiteando a defesa das Daniela Biondi et al.. 
áreas verdes (praças e espaços livres), através de uma ação popular.

Atualmente em Curitiba, na maioria dos bairros, o uso das praças é bastante limitado pela falta de segurança, a não ser quando estão situadas em locais com grande fluxo de pessoas. Embora, as praças apresentem bons atrativos sociais como os equipamentos obrigatórios para ginásticas, as pessoas ainda não se sentem seguras quando se encontram sozinhas.

Além da segurança das praças devem-se levar em consideração os anseios da comunidade. Robba e Macedo (2010) recomendam que na escolha da área a se implantar uma praça devem-se avaliar a distribuição e acessibilidade dos espaços livres dentro do tecido urbano e o programa de atividades deve ser estabelecido para contemplar as necessidades da comunidade que usará esse espaço. A desconsideração desses fatores cria espaços livres públicos que não cumprem sua função na cidade, permanecendo sem apropriação pública e fadados ao esquecimento.

Na TABELA 2 observa-se que $40 \%$ dos IAPH (Índice de área de praça por habitante) encontram-se abaixo de 1. Isto indica que um habitante possui menos de $1 \mathrm{~m}^{2}$ de área de praça. É um valor muito baixo para uma praça com ou sem vegetação.

Tabela 2. Distribuição das áreas de praças nos bairros da cidade de Curitiba-PR

\begin{tabular}{|c|c|c|c|c|c|}
\hline Bairros & $\begin{array}{c}\text { Área das } \\
\text { Praças }\left(\mathbf{m}^{2}\right)\end{array}$ & $\begin{array}{c}\text { Área do } \\
\text { Bairro }\left(\mathbf{m}^{2}\right)\end{array}$ & $\begin{array}{c}\text { Habitantes } \\
(2010)\end{array}$ & IAPH & IAPB(\%) \\
\hline Abranches & 23.049 & 4.318 .000 & 12.624 & 1,83 & 0,53 \\
\hline Água Verde & 52.174 & 4.764 .000 & 53.228 & 0,98 & 1,10 \\
\hline Ahú & 12.395 & 1.844 .000 & 11.503 & 1,08 & 0,67 \\
\hline Alto Boqueirão & 113.583 & 12.112 .000 & 57.027 & 1,99 & 0,94 \\
\hline Alto da Glória & 8.318 & 882.000 & 5.648 & 1,47 & 0,94 \\
\hline Alto da Rua XV & 32.042 & 1.504 .000 & 8.968 & 3,57 & 2,13 \\
\hline Atuba & 29.506 & 4.269.000 & 14.147 & 2,09 & 0,69 \\
\hline Augusta & 8.536 & 8.841 .000 & 4.576 & 1,87 & 0,10 \\
\hline Bacacheri & 67.281 & 6.981 .000 & 25.486 & 2,64 & 0,96 \\
\hline Bairro Alto & 43.550 & 7.018.000 & 46.530 & 0,94 & 0,62 \\
\hline Barreirinha & 43.932 & 3.733 .000 & 19.122 & 2,30 & 1,18 \\
\hline Batel & 6.062 & 1.760 .000 & 12.101 & 0,50 & 0,34 \\
\hline Bigorrilho & 16.642 & 3.503 .000 & 30.065 & 0,55 & 0,48 \\
\hline Boa Vista & 19.980 & 5.136 .000 & 32.248 & 0,62 & 0,39 \\
\hline Bom Retiro & 4.043 & 1.944 .000 & 5.707 & 0,71 & 0,21 \\
\hline Boqueirão & 97.392 & 14.802 .000 & 73.531 & 1,32 & 0,66 \\
\hline Butiatuvinha & 9.246 & 10.583 .000 & 12.135 & 0,76 & 0,09 \\
\hline Cabral & 3.172 & 2.040 .000 & 12.337 & 0,26 & 0,16 \\
\hline Cachoeira & 9.682 & 3.069 .000 & 8.899 & 1,09 & 0,32 \\
\hline Cajuru & 50.872 & 11.552 .000 & 98.414 & 0,52 & 0,44 \\
\hline Camp. do Siqueira & 7.534 & 1.693 .000 & 8.778 & 0,86 & 0,45 \\
\hline Campo Comprido & 85.347 & 8.549 .000 & 25.267 & 3,38 & 1,00 \\
\hline Campo de Santana & 21.359 & 21.574 .000 & 8.312 & 2,57 & 0,10 \\
\hline Capão da Imbúia & 9.100 & 3.163 .000 & 23.328 & 0,39 & 0,29 \\
\hline Capão Raso & 30.324 & 5.063 .000 & 38.145 & 0,79 & 0,60 \\
\hline Cascatinha & 5.688 & 2.567 .000 & 3.439 & 1,65 & 0,22 \\
\hline Caximba & 0 & 8.167 .000 & 2.857 & 0,00 & 0,00 \\
\hline Centro & 129.748 & 3.297 .000 & 33.290 & 3,90 & 3,94 \\
\hline Centro Cívico & 69.851 & 965.000 & 4.925 & 14,18 & 7,24 \\
\hline CIC & 457.216 & 43.378 .000 & 172.573 & 2,65 & 1,05 \\
\hline Cristo Rei & 7.703 & 1.464 .000 & 14.580 & 0,53 & 0,53 \\
\hline Fanny & 13.281 & 1.996 .000 & 9.959 & 1,33 & 0,67 \\
\hline Fazendinha & 26.794 & 3.717 .000 & 29.191 & 0,92 & 0,72 \\
\hline Guabirotuba & 53.276 & 2.631 .000 & 12.558 & 4,24 & 2,02 \\
\hline Guaíra & 34.710 & 2.322.000 & 16.071 & 2,16 & 1,49 \\
\hline Guanchinho & 2.918 & 11.196 .000 & 8.232 & 0,35 & 0,03 \\
\hline Hauer & 50.328 & 4.021 .000 & 15.690 & 3,21 & 1,25 \\
\hline Hugo Lange & 8.890 & 1.150 .000 & 3.192 & 2,79 & 0,77 \\
\hline
\end{tabular}

DISTRIBUIÇÃO ESPACIAL E TOPONÍMIA... 


\begin{tabular}{|c|c|c|c|c|c|}
\hline Jardim Social & 25.659 & 2.772 .000 & 6.509 & 3,94 & 0,93 \\
\hline Jd Américas & 37.203 & 3.874 .000 & 15.905 & 2,34 & 0,96 \\
\hline Jd Botânico & 51.050 & 1.885 .000 & 6.113 & 8,35 & 2,71 \\
\hline Juvevê & 22.385 & 1.227 .000 & 11.562 & 1,94 & 1,82 \\
\hline Lindóia & 2.692 & 1.180 .000 & 9.582 & 0,28 & 0,23 \\
\hline Mercês & 22.102 & 3.276 .000 & 14.191 & 1,56 & 0,67 \\
\hline Mossunguê & 20.722 & 3.381 .000 & 6.431 & 3,22 & 0,61 \\
\hline Novo Mundo & 9.529 & 5.992 .000 & 46.754 & 0,20 & 0,16 \\
\hline Orleans & 0 & 5.121 .000 & 8.175 & 0,00 & 0,00 \\
\hline Parolin & 3.113 & 2.253 .000 & 13.582 & 0,23 & 0,14 \\
\hline Pilarzinho & 49.558 & 7.131 .000 & 30.850 & 1,61 & 0,69 \\
\hline Pinheirinho & 46.328 & 10.734 .000 & 54.734 & 0,85 & 0,43 \\
\hline Portão & 44.020 & 5.695 .000 & 51.136 & 0,86 & 0,77 \\
\hline Prado Velho & 12.249 & 2.430 .000 & 7.615 & 1,61 & 0,50 \\
\hline Rebouças & 25.460 & 2.982 .000 & 15.980 & 1,59 & 0,85 \\
\hline Riviera & 0 & s/informação & 0 & 0,00 & 0,00 \\
\hline São Braz & 30.008 & 5.006 .000 & 25.661 & 1,17 & 0,60 \\
\hline São Francisco & 29.485 & 1.363 .000 & 6.607 & 4,46 & 2,16 \\
\hline São João & 12.245 & 3.029 .000 & 4.149 & 2,95 & 0,40 \\
\hline São Lourenço & 0 & 2.255 .000 & 7.630 & 0,00 & 0,00 \\
\hline São Miguel & 0 & s/informação & 0 & 0,00 & 0,00 \\
\hline Seminário & 17.450 & 2.128 .000 & 9.456 & 1,85 & 0,82 \\
\hline Sítio Cercado & 199.290 & 11.123 .000 & 114.920 & 1,73 & 1,79 \\
\hline Sta Cândida & 23.947 & 10.325 .000 & 31.325 & 0,76 & 0,23 \\
\hline Sta Felicidade & 46.482 & 12.274 .000 & 28.135 & 1,65 & 0,38 \\
\hline Sta Quitéria & 10.600 & 2.088 .000 & 13.118 & 0,81 & 0,51 \\
\hline Sto Inácio & 9.193 & 2.716 .000 & 7.608 & 1,21 & 0,34 \\
\hline Tarumã & 27.819 & 4.167 .000 & 8.465 & 3,29 & 0,67 \\
\hline Tatuquara & 48.924 & 11.229 .000 & 47.439 & 1,03 & 0,44 \\
\hline Tingui & 0 & 2.107 .000 & 13.325 & 0,00 & 0,00 \\
\hline Uberaba & 130.366 & 14.086 .000 & 70.800 & 1,84 & 0,93 \\
\hline Umbará & 14.100 & 22.474 .000 & 16.978 & 0,83 & 0,06 \\
\hline Vila Izabel & 8.493 & 1.211 .000 & 12.780 & 0,66 & 0,70 \\
\hline Vista Alegre & 14.130 & 3.691 .000 & 11.656 & 1,21 & 0,38 \\
\hline Xaxim & 50.412 & 8.924 .000 & 60.633 & 0,83 & 0,56 \\
\hline
\end{tabular}

\section{LEGENDA:}

IAPH = Índice de área de praça por habitante; IAPB = Índice de área de praça por bairro.

Quanto ao IAPB (Índice de área de praça por bairro), $79 \%$ dos bairros estão abaixo de 1 . Também se pode considerar baixo. Observa-se que o bairro do Centro Cívico apresenta os dois índices (IAPH e IAPB) bem acima dos demais, 14,18 e 7,24, respectivamente. Estes altos índices devem ser devido as grandes áreas de jardins públicos que são agregados aos prédios públicos administrativos que têm mais a função estética do que social.

O panorama que a TABELA 2 apresenta é muito importante para se conhecer a distribuição do número praças numa cidade. Pode ser que 453 praças para cidade de Curitiba seja um bom número, considerando a existência de outras tipologias de áreas verdes, principalmente os parques. Mas, o que se pode notar com clareza é a falta de distribuição das praças, mesmo não considerando os bairros que ainda estão em expansão. Esta tipologia de área verde é muito importante para os bairros porque não necessita de grandes áreas como um parque e, além disso, pode atender as necessidades recreacionais locais sem gerar grandes deslocamentos e conseqüentemente menos poluição por não ter que precisar do automóvel.

Milano (1991b) destaca a importância de se estabelecer valores regionalizados quando se faz um estudo de áreas verdes urbanas de uma cidade, de forma a conhecer a variação entre seus diferentes bairros ou regiões.

\section{Toponímia das Praças de Curitiba}

Observa-se na FIGURA 4 que do total de praças (453) analisadas, 27,59\% não apresentaram nomenclaturas oficiais e por isso foram consideradas praças sem identificação.

Mais de $60 \%$ das praças apresentam topônimos denominados de antropotoponímicos que referem-se 
aos nomes das pessoas. Os nomes oficiais encontrados nas praças são relativos a personagens do contexto histórico, político e artístico municipal, nacional e internacional, tais como: Praça Tiradentes, Praça Rui Barbosa, Praça Renato Russo e Praça Faraó Akhenaton.
Os topônimos geográficos representaram 4,64\% das praças da cidade e remete aos nomes de lugares, como: Praça Emirados Árabes Unidos, Praça Cidade de Mainz, Praça República da Islândia, Praça Cova da Iria, Praça da Grécia, Praça da Espanha, Praça Portugal, Praça da Ucrânia, Praça do Japão, etc.

Figura 4. Topônimos das praças de Curitiba/PR

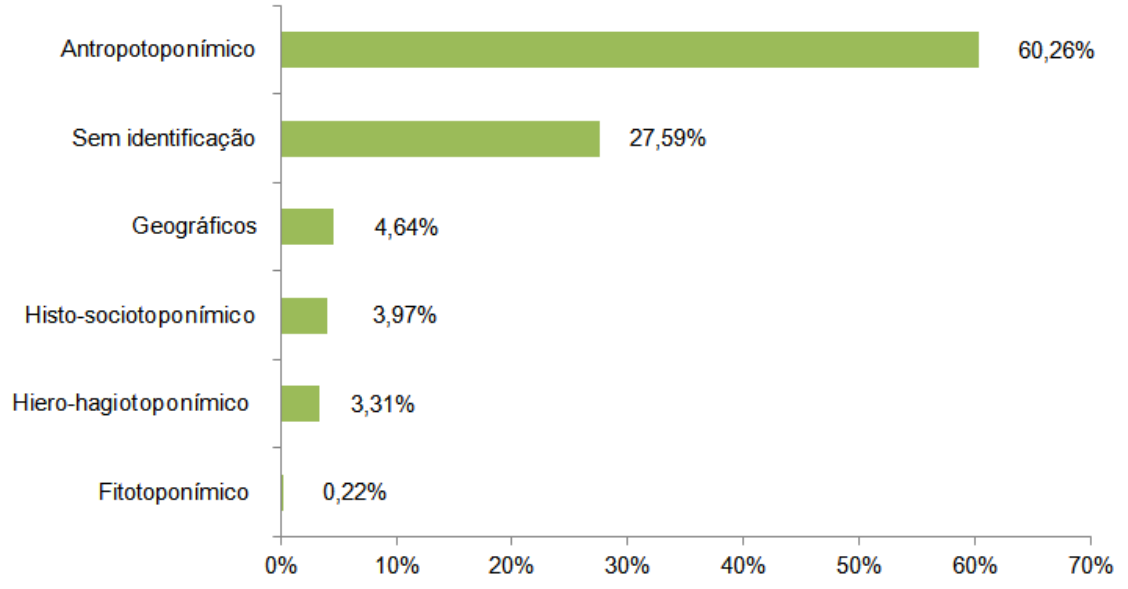

O topônimo denominado de histo-sociotoponímico foi representado por 3,97\% e é relativo aos nomes de fatos acontecidos e datas de caráter social e/ou histórico, como nestes são exemplos: Praça da Liberdade, Praça 12 de Outubro, Praça das Tendas, Praça da Primavera, Praça da Conquista, entre outras (FIGURA 4). Segundo Borella et al. (2011), a história demonstra a importância dos nomes que se dá aos logradouros públicos. Esses registram no tempo, a evolução sócio-política de um lugar e são espelhos de uma época e, mutáveis que são, retratam a dinamicidade própria da evolução da urbe.

As praças com nomes sagrados têm topônimos denominados de Hiero-hagiotoponímico. Foram encontrados 3,31\% das praças municipais com este topônimo, como por exemplos: Praça São Francisco de Assis, Praça Nossa Senhora Do Carmo, Santa Filomena, Praça do Redentor e Praça Santa Helena.

Com o topônimo chamado de fitotoponímico, referente ao nome de planta, foi encontrado apenas uma praça - Recanto dos Eucaliptos (FIGURA 4). Este resultado não foi esperado, já que Curitiba é uma cidade que prestigia e preserva tanto a natureza. A cidade apresenta tantas ruas bem arborizadas e remanescentes florestais, deveria ter mais nomes de ruas e praças homenageando a flora local ou brasileira.

Os critérios adotados para os nomes das praças públicas de Curitiba são os mesmos no panorama mundial. Segundo De Angelis e De Angelis Neto (2001), ora se homenageia um pioneiro local, ora um vulto histórico, um santo, uma data, um benemérito social, quando não uma cidade, um espécime da flora ou fauna.

O nome dos lugares lança luz sobre a evolução das cidades e abre novas perspectivas para o estudo da urbanização, da vida e do espaço urbano em geral (MARX, 1996). O conhecimento e análise acurada dos topônimos das praças permite que se conheça a história desses espaços ao longo do tempo (DE ANGELIS et al., 2004).

O uso dos topônimos das praças pode ser aplicado desde o planejamento paisagístico desta área, fazendo uma associação do nome com os elementos de composição. Quando a praça, por exemplo, tiver o nome de um médico, deve-se procurar criar algum 
canteiro com plantas medicinais e colocá-lo em destaque, principalmente se houver um busto desta pessoa. Provavelmente, o conhecimento e a consideração do topônimo no planejamento da praça será uma forma de criar um vínculo da população com a área verde. Esta atitude dos planejadores trará benefícios para ambas as partes, através do respeito e da conservação das áreas públicas.
Robba e Macedo (2010) corroboram com as questões acima afirmando que os espaços livres também são simbolicamente importantes, pois se tornam objetos referenciais e cênicos da paisagem da cidade, exercendo importante papel na identidade do bairro ou da rua.

\section{CONCLUSÕES}

Com os resultados dos índices IAPH (índice de áreas de praças nas regionais por habitante), IAPR (índice de área de praça por regional), e o NPR (número de praças por regional) foi possível detectar a distribuição das praças nas regionais administrativas de Curitiba. Os maiores valores destes índices nas regionais variaram em função da taxa de urbanização, sendo que o maior IAPH foi para a regional CIC e os maiores IAPR e o NPR ocorreram na regional Matriz. Para os índices IAPH (índice de área de praça por habitante) e IAPB (índice de área de praça por bairro), a atenção ficou voltada para os seis bairros com os índices iguais a zero, já que os maiores índices corresponderam aos mesmos resultados dos índices regionais. A provável justificativa para este resultado foi o pequeno número de habitantes dos bairros e a sua proximidade com grandes parques.

Os resultados destes índices podem auxiliar muito no planejamento das áreas verdes da cidade, com ênfase em praças. Além disso, estas informações podem justificar tanto a falta de uso e abandono de praças como a carência de praças de determinados locais e/ou solicitação de áreas verdes pelos munícipes.

Quanto aos nomes, a grande maioria das praças apresentou topônimos denominados de antropotoponímicos referentes aos nomes de pessoas e não aos nomes de plantas como se esperava pelo renome que a Curitiba carrega de "Cidade Ecológica”.

\section{REFERÊNCIAS BIBLIOGRÁFICAS}

ARDER, I. C. F.; RIBEIRO, R. de C. S.; TAVARES, A. R. Índices de área verde e cobertura vegetal para as praças do município de Vinhedo, SP. Revista Árvore, Viçosa, MG, v. 30, n. 2, p. 277-282, 2006.

BIONDI, D. Arborização urbana aplicada à educação ambiental nas escolas. Curitiba: o autor, 2008. 120p.

BIONDI, D. Caracterização do estado nutricional de Acer negundo L. e Tabebuia chrysotricha (Mart, ex DC.) Standl utilizadas na arborização urbana de Curitiba. Curitiba-PR, 1995. Tese (Doutorado em Engenharia Florestal), Ciências Agrárias, Universidade Federal do Paraná. 146p.

BIONDI, D. Curso de Arborização Urbana. Curitiba-PR: UFPR, 2000. 45p.

BORELLA, H. D.; PIVETTA, K. F. L.;ZANCHETA, A. A.; SILVA, M. T.; GIMENES, R. Revitalização e análise crítica da Praça Ernesto Poli, Jaboticabal - $\quad$ SP. Disponível em: http://prope.unesp.br/xxi_cic/27_35099083846.pdf>. Acesso em: 10/09/2011.

BURgos, M. B. Favela, Cidade e Cidadania em Rio das Pedras. In: BURGOS, M. B. (Org.). A Utopia da Comunidade Rio das Pedras, uma Favela Carioca. Rio de Janeiro: Loyola, 2003.

CARNEIRO, A. R. S.; MESQUITA, L. B. Espaços livres do Recife. Recife, Prefeitura da cidade do Recife, UFPE, 2000.

CAVALHEIRO, F.; NUCCI, J. C.; GUZZO, P.; ROCHA, Y. T. Proposição de Terminologia para o Verde Urbano . In: BOLETIM INFORMATIVO DA SBAU. Ano VII, no 3 Rio de Janeiro, RJ: SBAU, 1999.

COSTA, S. K.; SILVA JUNIOR, M. F.; RANGEL, M. C.; O processo de intervenção em espaços públicos urbanos dos usuários: praças públicas. REDE - Revista Eletrônica do PRODEMA, v. 4, n.1, p. 25-35, 2010.

Daniela Biondi et al.. 
DE ANGELIS, B. L. D.;DE ANGELIS NETO, G. Os topônimos das praças de Maringá, Estado do Paraná. Acta Scientiarum, v. 23, n. 6, p. 1561-1567, 2001.

DE ANGELIS, B. L.; CASTRO, R. M.; DE ANGELIS NETO, G. Metodologia para levantamento, cadastramento, diagnóstico e avaliação de praças no Brasil. Engenharia Civil • UM, Número 20, p. 57-70, 2004

DOURADO, L. A. C. A territorialidade na cidade e na praça: em foco, a Estância Turística Ilha Solteira - SP. GeoInterAÇÃO, v. 1, nº. 1, p. 20 - 38, 2009.

GONÇALVES, W. Urbana Paisagem 3: Palestras e Conferências - 2008/2009. Viçosa: o autor, 2010.

GRIFFITH, J. J.; SILVA, S. M. F. Mitos e métodos do planejamento de sistemas de áreas verdes. In: ENCONTRO NACIONAL SOBRE ARBORIZAÇÃO URBANA, 2., Maringá, 1987. Anais... Maringá, 1987. p 34-42.

GUZZO, P. Áreas Verdes. Disponível em: $<$ http://educar.sc.usp.br/biologia/ prociencias/areasverdes.html. Acesso em: agosto de 2002.

HARDT, L.P.A. Subsídios à Gestão da Qualidade da Paisagem Urbana: Aplicação a Curitiba-PR. Curitiba-PR: 2000. Tese (Doutorado em Engenharia Florestal), Setor de Ciências Agrárias, Universidade Federal do Paraná. 323f.

IPPUC - Instituto de Pesquisa e Planejamento Urbano de Curitiba. Curitiba em Dados. Disponível em: $<$ http://www.ippuc.org.br/Bancodedados/Curitibaemdados/Curi tiba_em_dados_Pesquisa.asp?ampliar=não>. Acesso em: janeiro de 2011.

KRUG, H. P. Problemas de ajardinamento e arborização públicas. São Paulo: Serviço Florestal. 32p.1953.

LIZ - Leis Municipais. Disponível em: < http://www.leismunicipais.com.br/legislacao-de-curitiba/738561/decreto427-1983-curitiba-pr.html>. Acesso em: janeiro de 2011.

MACEDO, S. S.; SAKATA, F. M. G. Parques urbanos no Brasil. São Paulo: EDUSP / Imprensa Oficial, 2002.

MACEDO,S. S. O paisagismo moderno brasileiro - além de Burle Marx. Paisagens em Debate, n. 01, p. 1-7, 2003.

MARX, M. Apresentação. In: DICK, M.V.P.A. A dinâmica dos nomes na cidade de São Paulo 1554-1897. São Paulo: Annablume, 1996.

MILANO, M. S. Curso sobre Arborização Urbana. Curitiba-PR: FUPEF, 1991. 76p.

MILANO, M. S. Planejamento da Arborização Urbana: Relações entre áreas verdes e ruas arborizadas. In: ENCONTRO NACIONAL SOBRE ARBORIZAÇÃO URBANA, III (1990: Curitiba-PR). Anais... FUPEF / UFPR: 1990. p. 60-71

PADRON, A. G.; CLAVERO, N. P.; SÁNCHEZ, B. V. La planificación de lãs áreas verdes em La ciudad de La Havana. In: CONGRESSO IBEROAMERICANO DE PARQUES Y JARDINES PÚBLICOS, II. Anais... HabanaCuba. 2001.

ROBBA, F.; MACEDO, S. S. Praças Brasileiras. 3ª ed. São Paulo: Editora da Universidade de São Paulo, 2010. (Coleção Quapá).

RODERJAN, C. V.; GALVÃO, F.; KUNIYOSHI, Y. S.; HATSCHBACH, G. G. As regiões fitogeográficas do Estado do Paraná. Revista Ciência e Ambiente, 24, jan/jun 2002. 75-92p

SANTOS, L. I. R. Proposta de um modelo Conceitual-teórico para a manutenção de Praças públicas no município de Vitória-ES: estudo de caso. Dissertação (Mestrado em Engenharia Civil) - Universidade Federal do Espírito Santo, Centro Tecnológico. 110f. 2007

SMMAC - Secretaria Municipal de Meio Ambiente de Curitiba. Parques e Bosques. Disponível em: http://www.curitiba.pr.gov.br/secretaria.aspx?o=5.>. Acesso em fevereiro de 2006.

VELOSO FILHO, H. P.; RANGEL, A. L. R.; LIMA, J.C.A. Classificação da Vegetação Brasileira Adaptada a um Sistema Universal. Rio de Janeiro-RJ: IBGE, 1991.

VIEIRA, C. H. S. D. Estudo da dinâmica da cobertura vegetal de Curitiba / PR com o uso de imagens digitais. Curitiba, 2006. 165 f. Dissertação (Mestrado em Engenharia Florestal) - Setor de Ciências Agrárias, Universidade Federal do Paraná.

VIEIRA, C. H. S. D.; BIONDI, D. Análise da dinâmica da cobertura vegetal de Curitiba, PR (de 1986 A 2004), utilizando imagens Landasat TM. Revista Árvore, v.32, n.3, p. 479-487, 2008.

VIERO, V. C.; BARbOSA FILHO, L. C. Praças Públicas: Origem, Conceitos e Funções. In: JORNADA DE PESQUISA E EXTENSÃO. Anais... ULBRA - Santa Maria, p.1-3, 2009. 